\title{
Sub-15 nm Silicon Lines Fabrication via PS-b-PDMS Block Copolymer Lithography
}

\author{
Sozaraj Rasappa, ${ }^{1,2}$ Lars Schulte, ${ }^{1,2}$ Dipu Borah, ${ }^{3,4,5}$ \\ Michael A. Morris, ${ }^{3,4,5}$ and Sokol Ndoni ${ }^{1,2}$ \\ ${ }^{1}$ Department of Micro and Nanotechnology, Technical University of Denmark, 2800 Kongens Lyngby, Denmark \\ ${ }^{2}$ Center for Nanostructured Graphene CNG, Technical University of Denmark, 2800 Kongens Lyngby, Denmark \\ ${ }^{3}$ Materials Section, Department of Chemistry, University College Cork, Cork, Ireland \\ ${ }^{4}$ Centre for Adaptive Nanostructures and Nanodevices (CRANN), Trinity College Dublin, Dublin 2, Ireland \\ ${ }^{5}$ Tyndall National Institute, Lee Maltings, Prospect Row, Cork, Ireland
}

Correspondence should be addressed to Sokol Ndoni; sond@nanotech.dtu.dk

Received 15 September 2013; Revised 30 September 2013; Accepted 2 October 2013

Academic Editor: Amir Kajbafvala

Copyright (C) 2013 Sozaraj Rasappa et al. This is an open access article distributed under the Creative Commons Attribution License, which permits unrestricted use, distribution, and reproduction in any medium, provided the original work is properly cited.

This paper describes the fabrication of nanodimensioned silicon structures on silicon wafers from thin films of a poly(styrene)block-poly(dimethylsiloxane) (PS- $b$-PDMS) block copolymer (BCP) precursor self-assembling into cylindrical morphology in the bulk. The structure alignment of the PS- $b$-PDMS (33k-17k) was conditioned by applying solvent and solvothermal annealing techniques. BCP nanopatterns formed after the annealing process have been confirmed by scanning electron microscope (SEM) after removal of upper PDMS wetting layer by plasma etching. Silicon nanostructures were obtained by subsequent plasma etching to the underlying substrate by an anisotropic dry etching process. SEM images reveal the formation of silicon nanostructures, notably of sub-15 nm dimensions.

\section{Introduction}

Continuing miniaturisation of microelectronics and nanoelectronics devices strongly demands controlled high density nanodimensioned structures in wafer scale [1-4]. Feature size reduction is conventionally achieved following the usage of UV, e-beam, and X-ray lithographic processes, for obtaining sub-22 $\mathrm{nm}$ device structures [5]. These topdown methodologies of device fabrication are already well established in silicon industries for chip miniaturisation in large scale [6]. They utilize highly expensive light sources [7], while attainment of smaller length-scale features is getting increasingly challenging and time consuming due to the intrinsic serial nature of the top-down methodology [8]. Alternative intrinsically parallel methodologies based on bottom-up approaches that exploit block copolymer (BCP) self-assembly as nanostructure generator are becoming increasingly attractive among researchers [9]. The potential of such approaches is to generate predictable sub-10 nm structures at low costs [10, 11]. BCPs like polystyrene- $b$-polymethylmethacrylate (PS- $b$-PMMA), polystyrene- $b$-polylacticacid (PS- $b$-PLA), polystyrene- $b$-polydimethylsiloxane (PS- $b$-PDMS), and polystyrene- $b$-polyethyleneoxide (PS- $b$-PEO) of lamellar, cylindrical, or spherical morphology in combination with different strategies for control of substrate surface chemistry and pattern alignment have been used as precursors for nanolithographic masks $[12,13]$. Many applications have been demonstrated for nanostructures made by these BCPs, for example, in the fields of magnetic, metal oxide, and metallic device fabrication [14]. However, challenges exist in getting highly packed device features [15] generated through BCPs.

Nanolithographic mask fabrication from BCPs often requires lamella or cylinder alignment perpendicular to the substrate, and this has been achieved by rendering the substrate surface energy neutral relative to the two blocks $[16,17]$. Covalent anchoring of hydroxyl-terminated homopolymers or random copolymers onto substrate is one 
TABLE 1: Details of synthesised polymer characteristics used for the present work.

\begin{tabular}{lcccc}
\hline $\begin{array}{l}\text { Molecular weight, } \\
M_{n}, \mathrm{~g} / \mathrm{mol}\end{array}$ & $\begin{array}{c}\text { Polydispersity, } \\
M_{w} / M_{n}\end{array}$ & $\begin{array}{c}\text { Molecular weight of PS, } \\
M_{n(\mathrm{PS})}, \mathrm{g} / \mathrm{mol}\end{array}$ & $\begin{array}{c}\text { Volume fraction } \\
\text { of PS, } f_{\mathrm{PS}}\end{array}$ & Description \\
\hline 50000 & 1.03 & 17000 & 0.64 & PS- $b$-PDMS \\
11000 & 1.05 & - & - & PS-OH \\
\hline
\end{tabular}

of the most effective techniques of surface modification for perpendicular alignment of BCPs [18]. It should be noted that the majority of the studies has been devoted to BCPs like PS- $b$-PMMA, PS- $b$-PLA, and PS- $b$-PEO. However, PS$b$-PDMS is of particular interest due to its relatively large Flory-Huggins interaction parameter $(\chi \sim 0.26)$, larger than the interaction parameters of the BCPs mentioned above $[19,20]$. These BCPs allow for smaller minimum feature size dimensions that are certainly below the feature size realized by the established UV-lithography method [21-23]. The fabrication of sub- $15 \mathrm{~nm}$ and possibly sub-10 $\mathrm{nm}$ feature size structures becomes possible by appropriate design of nanolithographic masks from PS- $b$-PDMS.

In this paper, we demonstrate the fabrication of sub- $15 \mathrm{~nm}$ silicon nanowires from a synthesized PS- $b$-PDMS (33k$17 \mathrm{k}$ ) of total molecular weight of $50 \mathrm{~kg} / \mathrm{mol}$ and a hydroxyl terminated PS brush. Device structures are formed using plasma dry etching where BCP patterns act as a mask and are transferred into the underlying substrate. It should be noted that PS- $b$-PDMS self-assembly results in the formation of sandwich structures with wetting PDMS layers at the substrate-polymer and polymer-air atmospheres [24]. This involves a prior selective etch process of an upper PDMS layer followed by silicon etch.

\section{Materials and Methods}

2.1. Materials. Silicon $\langle 100\rangle$ wafers (p-type) were used with a native oxide layer $\sim 2 \mathrm{~nm}$. A hydroxyl-terminated polystyrene, denoted as PS-OH brush, and a block copolymer poly(styrene)-block-poly(dimethylsiloxane) (PS- $b$-PDMS) were synthesised in our own lab by "living" anionic polymerisation [25, 26]. Detailed characteristics of the polymers are summarized in Table 1. Toluene (99.8\%) was purchased from Sigma-Aldrich and used without further purification. Deionised (DI) water was used wherever it was essential.

2.2. Preparation of PS-OH Brush Anchored Substrates. Substrates were cleaned in SPTS inductively coupled plasma (ICP) etch tool by an oxygen plasma of flow rate $30 \mathrm{sccm}$ for $180 \mathrm{~s}$ at $2.0 \mathrm{~Pa}$ with $1500 \mathrm{~W}$ and $200 \mathrm{~W}$ of ICP and reactiveion-etch (RIE) power. This effectively removes organic contaminants from the substrates. Hydroxyl-terminated PS solution of $1.0 \mathrm{wt} \%$ in toluene was spin-coated onto silicon substrates at $3200 \mathrm{rpm}$ for $30 \mathrm{~s}$. Samples were baked at $443 \mathrm{~K} \mathrm{~s}$ for $4 \mathrm{~h}$, which resulted in the formation of a polymer brush anchored onto substrates due to condensation reaction between hydroxyl groups of PS-OH and of silicon native oxide layer.
2.3. PS-b-PDMS Deposition on Brush Anchored Substrates. PS- $b$-PDMS solution of $1.0 \mathrm{wt} \%$ in toluene was spin-coated on silicon substrates modified with the PS-OH brush at $3200 \mathrm{rpm}$ for $30 \mathrm{~s}$. The substrates covered with BCP thin film on top of the brush layer were then solvent-annealed in a glass jar under saturated toluene environment at $298 \mathrm{~K}$ or at $323 \mathrm{~K}$ for four different annealing times (varied from $3 \mathrm{~h}$ to $12 \mathrm{~h}$ ). Samples were removed from oven immediately after annealing and allowed to dry at ambient conditions.

2.4. Dry Plasma Etching of BCP Thin Films. After solvothermal annealing PS- $b$-PDMS films were subjected to removal of upper PDMS layer (and partial removal of PS matrix) using $\mathrm{CF}_{4}$ and $\mathrm{O}_{2}$ plasma with $15 \mathrm{sccm}$ and $30 \mathrm{sccm}$ for $15 \mathrm{~s}$ with ICP and RIE powers of $1200 \mathrm{~W}$ and $30 \mathrm{~W}$ at $1.6 \mathrm{~Pa}$ pressure. The oxidised PDMS cylinders act as hard mask for subsequent silicon etching by $\mathrm{SF}_{6}$ and $\mathrm{C}_{4} \mathrm{~F}_{8}$ plasma at $70 \mathrm{sccm}$ and $35 \mathrm{sccm}$ flow rate with ICP and RIE powers of $1200 \mathrm{~W}$ and $200 \mathrm{~W}$ at $1.9 \mathrm{~Pa}$ pressure.

2.5. Scanning Electron Microscopy (SEM). Top-down and cross-sectional SEM images of polymer mask templates and silicon nanostructures were obtained by using a high resolution field emission Zeiss Ultra Plus SEM with a Gemini column operating at an accelerated voltage of $3 \mathrm{keV}$.

\section{Results and Discussion}

The PS- $b$-PDMS BCP used in the study possesses a total molecular weight of $50 \mathrm{~kg} \mathrm{~mol}^{-1}$ and a PS volume fraction of $64 \%$ and shows a thermodynamic equilibrium structure of cylindrical PDMS domains in a PS matrix. BCP self-assembly of PS- $b$-PDMS $(33 \mathrm{k}-17 \mathrm{k})$ was achieved by techniques of solvent annealing and solvothermal annealing in saturated toluene environment at $298 \mathrm{~K}$ and $323 \mathrm{~K}$ with varying anneal time. Figures $1(\mathrm{a})-1(\mathrm{~h})$ show top-down SEM images of PS- $b$-PDMS patterns after solvent annealing at $298 \mathrm{~K}$ and solvothermal annealing at $323 \mathrm{~K}$ for a set of four different timings ( $3 \mathrm{~h}-12 \mathrm{~h})$.

The upper PDMS layer formed during self-assembly has been removed by using $\mathrm{CF}_{4}$ and $\mathrm{O}_{2}$ plasma for $15 \mathrm{~s}$ after which the nanopatterns became clearly visible in the SEM images (Figures 1(a)-1(h)). A schematic illustration of the workflow for the nanostructuring process is shown in Scheme 1.

Figures 1(a)-1(d) show top-down SEM images after etching of the upper PDMS wetting layer of solvothermal annealed samples at $298 \mathrm{~K}$ for $3 \mathrm{~h}, 6 \mathrm{~h}, 9 \mathrm{~h}$, and $12 \mathrm{~h}$, respectively, while Figures $1(\mathrm{e})-1(\mathrm{~h})$ show images of similar samples after solvothermal annealing at $323 \mathrm{~K}$ for $3 \mathrm{~h}, 6 \mathrm{~h}$, $9 \mathrm{~h}$, and $12 \mathrm{~h}$, respectively. It is clearly seen from Figure 1 that the sample annealed at $323 \mathrm{~K}$ for $3 \mathrm{~h}$ gives (Figure $1(\mathrm{e})$ ) 


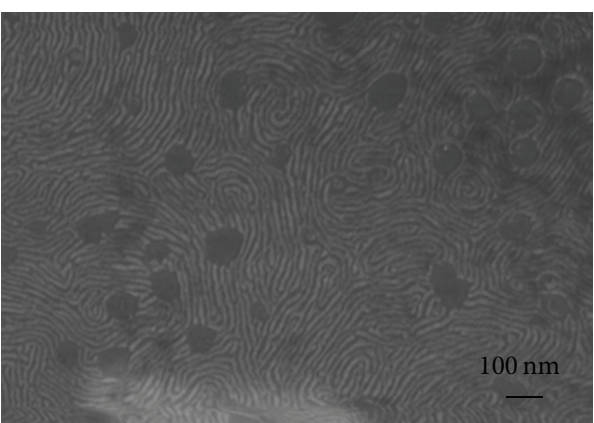

(a)

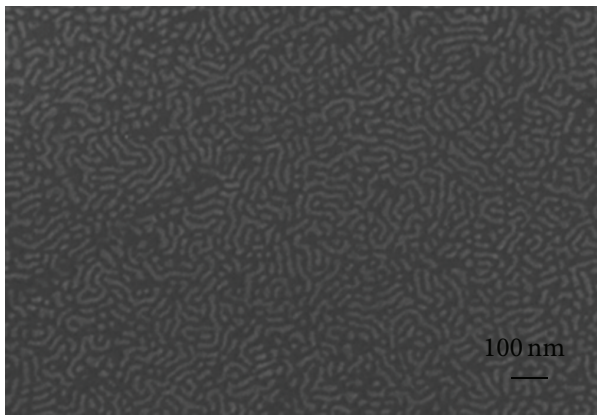

(c)

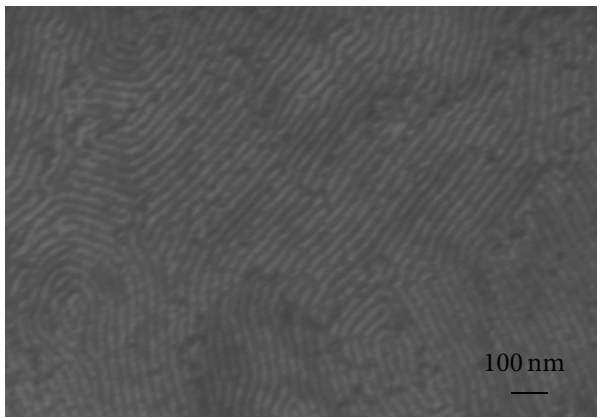

(e)

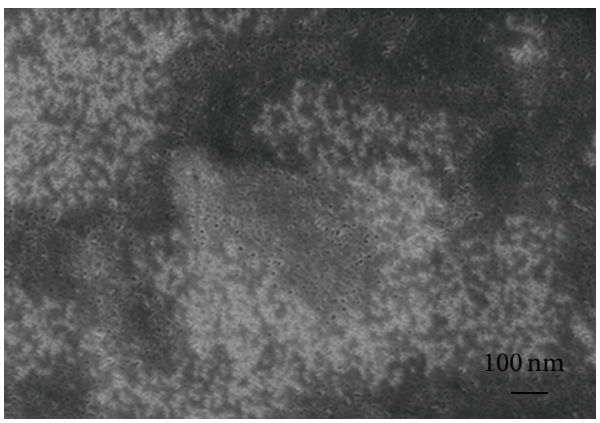

(g)

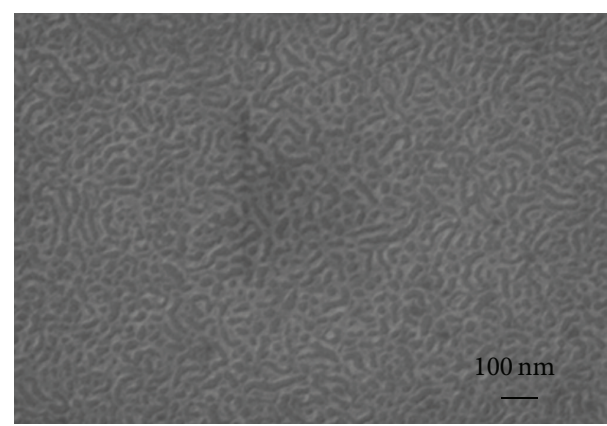

(b)

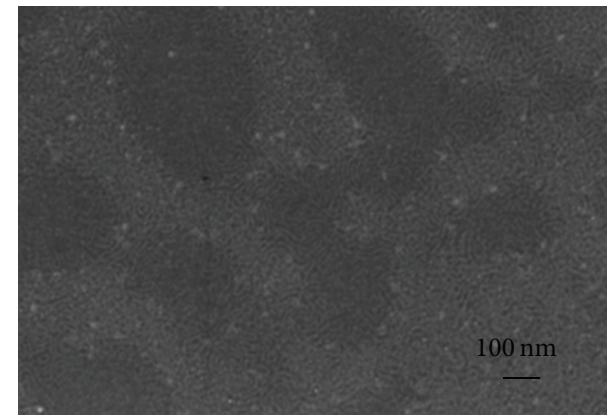

(d)

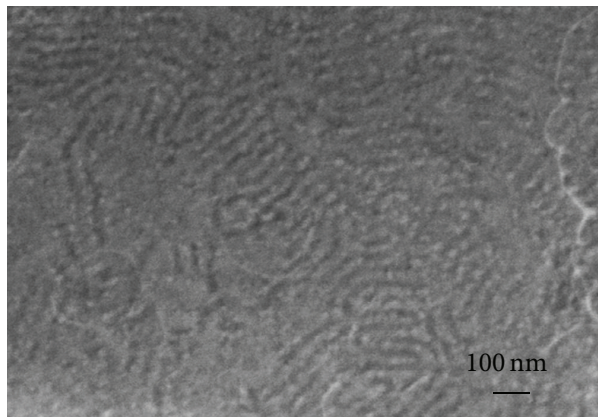

(f)

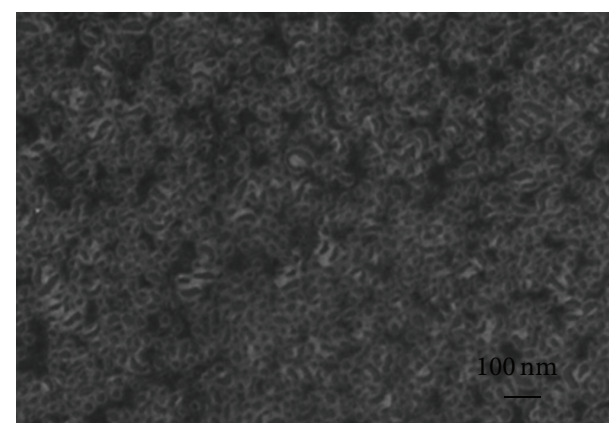

(h)

FIGURE 1: Top-down SEM images of self-assembled PS- $b$-PDMS on top of PS-OH anchored silicon substrates after treatment with $\mathrm{CF}_{4}+\mathrm{O}_{2}$ plasma. The plasma removes upper PDMS wetting layer and part of the PS matrix. All samples were annealed under toluene environment: (a) at $298 \mathrm{~K}$ for $3 \mathrm{~h}$; (b) at $298 \mathrm{~K}$ for $6 \mathrm{~h}$; (c) at $298 \mathrm{~K}$ for $9 \mathrm{~h}$; (d) at $298 \mathrm{~K}$ for $12 \mathrm{~h}$; (e) at $323 \mathrm{~K}$ for $3 \mathrm{~h}$; (f) at $323 \mathrm{~K} \mathrm{for} 6 \mathrm{~h}$; (g) at $323 \mathrm{~K}$ for $9 \mathrm{~h}$; and (h) at $323 \mathrm{~K}$ for $12 \mathrm{~h}$.

the best alignment of cylinders horizontal to the substrate. The mean PDMS cylinder spacing, $L_{0}$, and line width, $\langle d\rangle$, were about $31 \mathrm{~nm}$ and $15 \mathrm{~nm}$.
Among the tested annealing conditions it seems evident that the annealing for $3 \mathrm{~h}$ at $323 \mathrm{~K}$ produces best results in terms of cylindrical structure alignment and persistence 


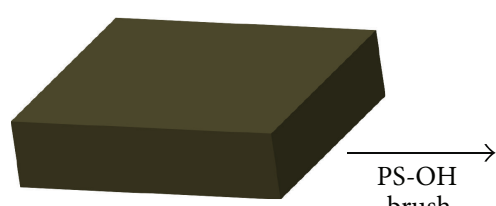

brush deposition

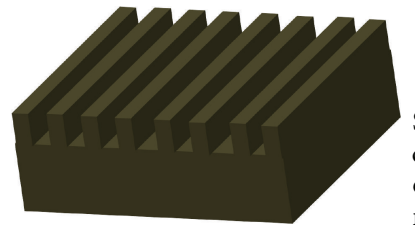

Silicon

PS-OH brush

Oxidised PDMS cylinders

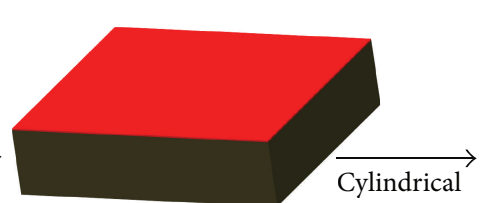

PS- $b$-PDMS

BCP

deposition

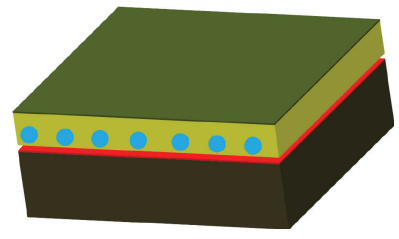

Selective etching of PDMS wetting layer and partial removal $\downarrow$ of PS matrix

Silicon nanostructures after complete pattern transfer + oxidised PDMS cylinders removal

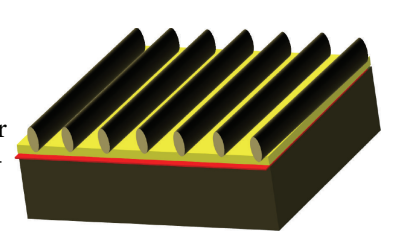

Scheme 1: Schematic of BCP self-assembly on top of PS-OH brush layer anchored on the surface of silicon substrates and subsequent plasma etching for silicon nanostructures fabrication [18].

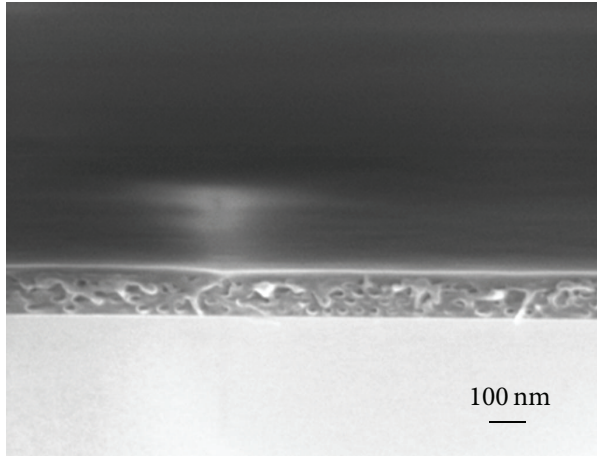

(a)

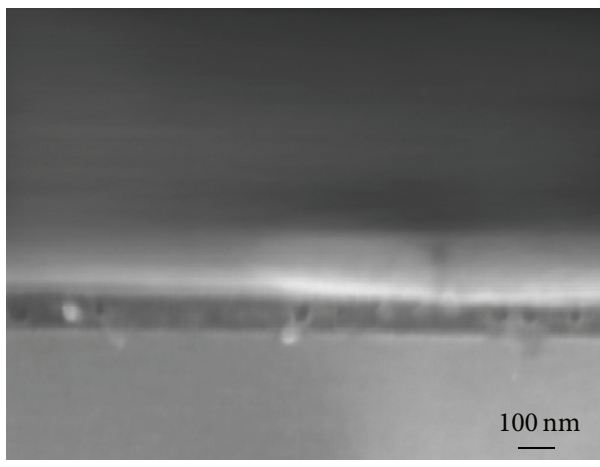

(c)

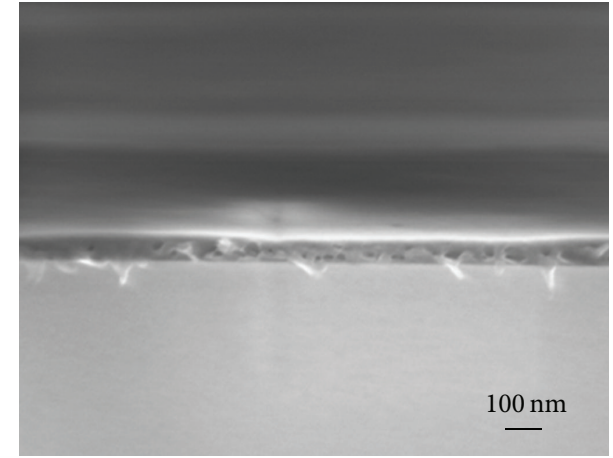

(b)

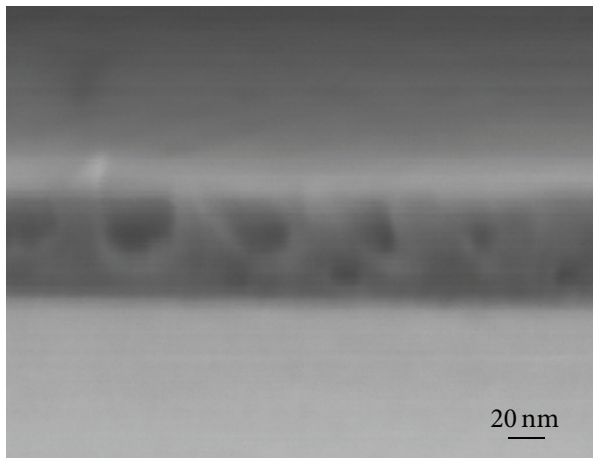

(d)

FIgURE 2: Cross-sectional SEM images of cylindrical structure of PS- $b$-PDMS after solvothermal annealing at $323 \mathrm{k}$ for $3 \mathrm{~h}$. No prior PDMS etch was done and most probably the thin top layer is the expected low surface energy PDMS wetting layer. (a) Multilayer, (b) bilayer, and (c) monolayer regions of PS-b-PDMS patterns. (d) High resolution cross-sectional image of cylindrical structures. 


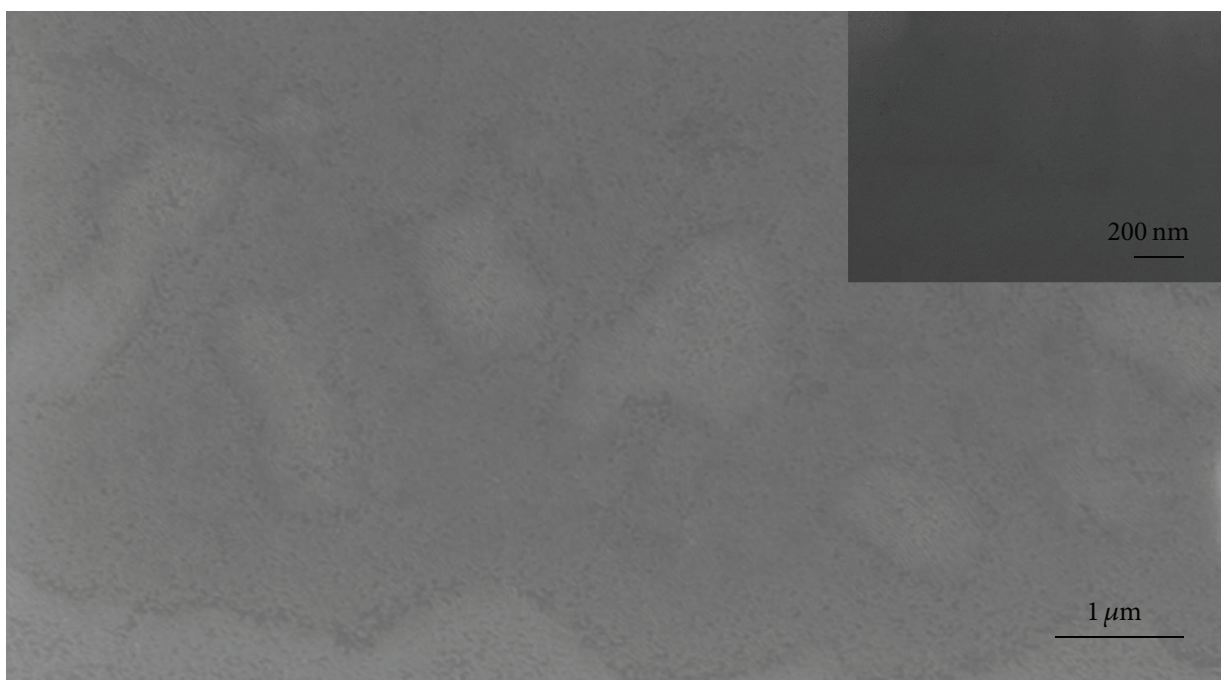

(a)

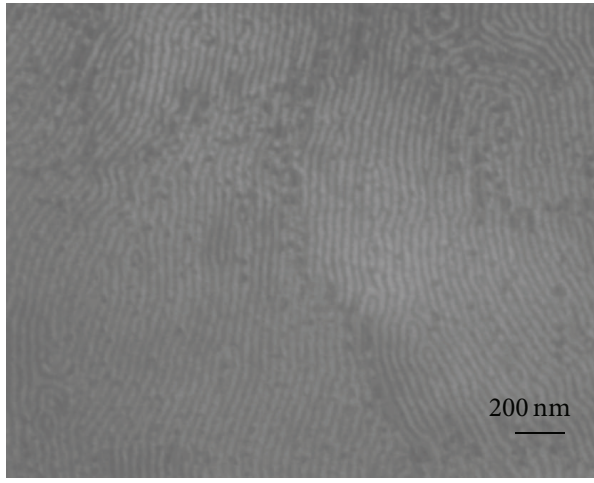

(b)

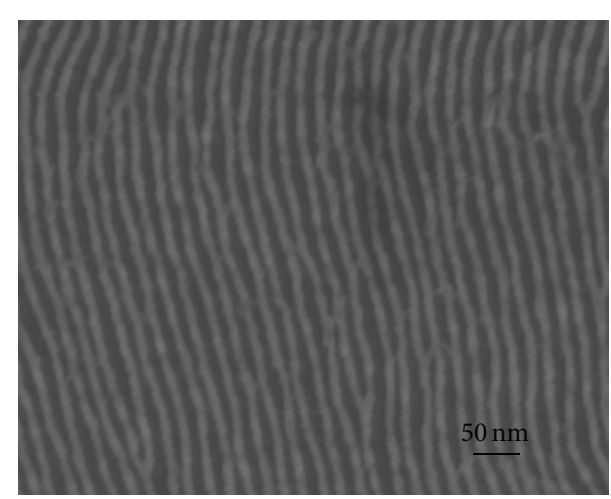

(c)

FIGURE 3: Top-down SEM images of PS- $b$-PDMS on $4^{\prime \prime}$ wafer. (a) Top-down SEM image of PS- $b$-PDMS after PDMS removal; inset shows PS- $b$-PDMS before removal of upper PDMS with no nanopattern visible. (b) Low resolution and (c) high resolution images of oxidised PDMS cylinders.

length. Annealing times above $6 \mathrm{~h}$ at $323 \mathrm{~K}$ favour short range structures and micelle formation, as seen in Figures $1(\mathrm{f})-1(\mathrm{~h})$.

PS- $b$-PDMS samples prepared at $323 \mathrm{~K}$ and $3 \mathrm{~h}$ solvothemal annealing were studied in more details. In order to get a better understanding of the cylindrical morphology of PS- $b$-PDMS, cross-sectional SEM images prior to any PDMS removal were taken as shown in Figure 2. Dewetting is one of the major issues in high $\chi$ BCP systems such as PS- $b$-PDMS, and this leads to multilayer formation in different regions upon solvothermal annealing process. Multilayer regions are clearly seen by cross-sectional SEM images (Figures 2(a)2(b)). Figure 2(a) shows the multilayer formation of PDMS cylinders in PS matrix horizontal to the planar substrates with a thin upper PDMS layer. However, most of the areas were covered with monolayer of PDMS cylinders shown in SEM images of Figure 2(c). A good pattern transfer to the underlying silicon substrate is expected on the monolayer regions. The wafer scale production of device structures using PS- $b$-PDMS $(33 \mathrm{k}-17 \mathrm{k})$ was examined on a 4 -inch wafer. A 4 -inch wafer cleaned with oxygen plasma was spin-coated firstly with PS-OH and baked and secondly with PS- $b$-PDMS and annealed at $323 \mathrm{~K}$ for $3 \mathrm{~h}$ in toluene environment. After the removal of the upper PDMS layer large area coverage of BCP patterns could be observed under SEM as shown in Figure 3(a) with minor dewetting. The PDMS cylinders get oxidised while removing upper PDMS layer by $\mathrm{CF}_{4}$ and $\mathrm{O}_{2}$ plasma, which results into a strong mask for a good pattern transfer to the silicon substrate.

Low resolution and high resolution images of oxidised PDMS cylinders are seen in Figures 3(b) and 3(c). The feature size of cylinders was $\sim 13 \mathrm{~nm}$ in the shown projection. The film regions nanopatterned by the oxidised PDMS threads were used as mask for pattern transfer in the silicon substrate. Silicon nanostructures were fabricated after a silicon etch of $15 \mathrm{~s}$ and $20 \mathrm{~s}$ using $\mathrm{CF}_{4}$ and $\mathrm{SF}_{6}$, respectively, with ICP and RIE powers of $600 \mathrm{~W}$ and $40 \mathrm{~W}$ under $1.2 \mathrm{~Pa}$ chamber pressure. Later the substrates were sonicated in $40 \% \mathrm{HF}$ for 5 min to remove oxidised PDMS cylinders and the results are shown in Figures 4(a) and 4(b). Silicon nanostructures were regular with feature size of about $12-15 \mathrm{~nm}$ for $15 \mathrm{~s}$ Si etch 


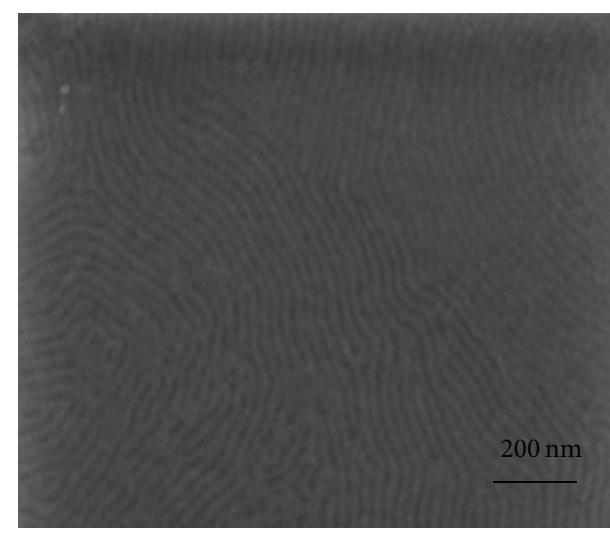

(a)

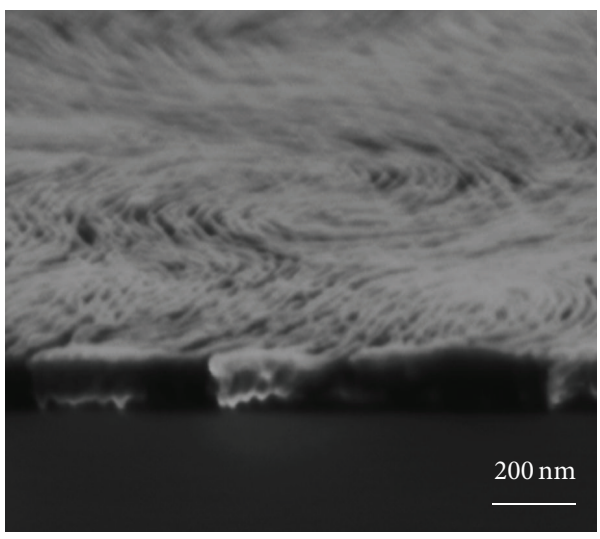

(c)

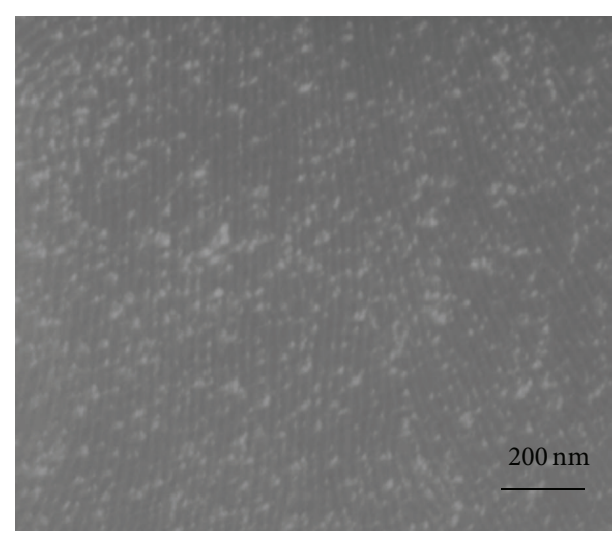

(b)

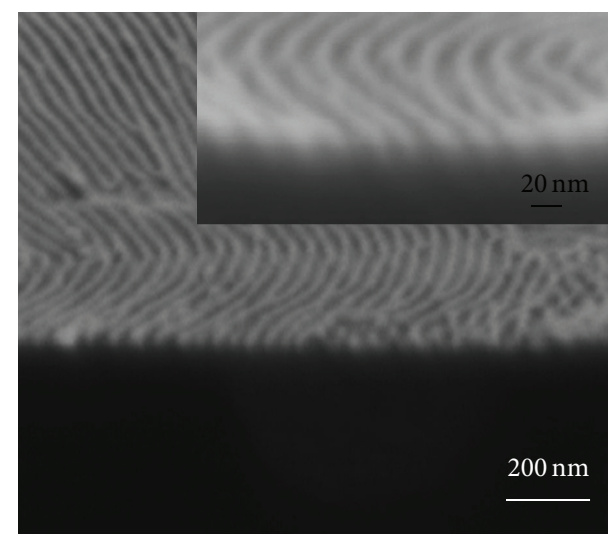

(d)

FIGURE 4: SEM images of silicon nanostructures. (a) Silicon nanowires after $15 \mathrm{~s}$ silicon etch. (b) Silicon nanostructures after $20 \mathrm{~s} \mathrm{silicon}$ etch. (c) No pattern transfer in bilayer and multilayer regions. (d) Complete pattern transfer in monolayer regions of PS- $b$-PDMS template. Inset (d) shows the high resolution image of nanowires.

(Figure 4(a)), whereas at $20 \mathrm{~s}$ etch time silicon structures were partially destroyed as shown in the top-down SEM image of Figure 4(b). There was no successful pattern transfer to the underlying silicon at the regions covered by multilayers as seen in the image of Figure 4(c). The multilayer structure prevents the plasma to strike down to the silicon substrate due to misalignment of PDMS cylinders in the different layers. It is clear from Figure 4(d) that there was an isotropic silicon etch resultant into the formation of silicon nanowires; the inset shows the high resolution SEM image of transferred nanostructures.

The minimum exposure of BCP film under toluene environment has a very little swelling or deformation of BCP patterns for shorter annealing time for $3 \mathrm{~h}$ at $323 \mathrm{~K}$. The orientation and coherence length of the film are also affected by the exposure time to toluene vapours. The silicon wires fabricated by this synthesised PS- $b$-PDMS block copolymer lie in the region of sub-15 nm. Although the results shown in this paper are similar to the literature reports (with respect to etch and feature size of wires), no literature has yet shown the self-assembly and subsequent pattern transfer of an inlab synthesised PS- $b$-PDMS. This indicates a gateway for very low cost production of device structures for microelectronics industries.

\section{Conclusions}

We have presented a qualitative and quantitative analysis of a solvent and solvothermal process for the fabrication of nanolithographic masks from PS- $b$-PDMS BCP of cylindrical morphology. The BCP was spin-casted on silicon wafer substrates surface modified by grafting of a PS-OH brush layer. The solvothermal annealing process was applied at two temperatures and four annealing times for each temperature. The conditions that produced line patterns with highest correlation length were $3 \mathrm{~h}$ annealing at $323 \mathrm{~K}$. The method showed a promising BCP self-assembly on planar silicon substrate. It must be notified that the obtained results on the thin film self-assembly of the synthesised PS- $b$-PDMS ( $33 \mathrm{k}-$ $17 \mathrm{k}$ ) were similar with the literature reports. Nanopattern transfer to underlying silicon substrates in the form of sub$15 \mathrm{~nm}$ wires for nanodevice fabrication via BCP self-assembly was demonstrated.

\section{Acknowledgments}

Financial support for this work is provided by The Center for Nanostructured Graphene sponsored by the Danish National Research Foundation, Project DNRF58. Financial 
support by the EU FP7 NMP project, LAMAND (Grant no. 245565), and the Science Foundation of Ireland (Grant no. 09/IN.1/602) is also acknowledged.

\section{References}

[1] M. Freebody, "Preserving moore's law pushes lithography to its limits," Photonics Spectra, vol. 45, no. 5, 2011.

[2] D. Borah, M. T. Shaw, S. Rasappa et al., "Plasma etch technologies for the development of ultra-small feature size transistor devices," Journal of Physics D, vol. 44, no. 17, Article ID 174012, 2011.

[3] C. A. MacK, "Fifty years of Moore's law," IEEE Transactions on Semiconductor Manufacturing, vol. 24, no. 2, pp. 202-207, 2011.

[4] S. Rasappa, D. Borah, S. Ramsankar et al., "Block copolymer lithography: feature size control and extension by an over-etch technique," Thin Solid Films, vol. 522, no. 1, pp. 318-323, 2011.

[5] A. V. Pret, P. Poliakov, R. Gronheid et al., "Linking EUV lithography line edge roughness and $16 \mathrm{~nm}$ NAND memory performance," Microelectronic Engineering, vol. 98, no. 2, pp. 2428, 2012.

[6] A. Biswas, I. S. Bayer, A. S. Biris, T. Wang, E. Dervishi, and F. Faupel, "Advances in top-down and bottom-up surface nanofabrication: techniques, applications \& future prospects," Advances in Colloid and Interface Science, vol. 170, no. 1-2, pp. 2-27, 2012.

[7] A. E. Grigorescu and C. W. Hagen, "ZResists for sub-20-nm electron beam lithography with a focus on HSQ: state of the art," Nanotechnology, vol. 20, no. 29, Article ID 292001, 2009.

[8] S. V. Sreenivasan, J. Choi, P. Schumaker, and F. Xu, "4. 04status of UV imprint lithography for nanoscale manufacturing," Comprehensive Nanoscience and Technology, vol. 4, pp. 83-116, 2011.

[9] S. B. Darling, "Directing the self-assembly of block copolymers," Progress in Polymer Science (Oxford), vol. 32, no. 10, pp. 11521204, 2007.

[10] H.-W. Li and W. T. S. Huck, "Ordered block-copolymer assembly using nanoimprint lithography," Nano Letters, vol. 4, no. 9, pp. 1633-1636, 2004.

[11] I. Bita, J. K. W. Yang, S. J. Yeon, C. A. Ross, E. L. Thomas, and K. K. Berggren, "Graphoepitaxy of self-assembled block copolymers on two-dimensional periodic patterned templates," Science, vol. 321, no. 5891, pp. 939-943, 2008.

[12] T. Ghoshal, S. Ramsankar, M. T. S. Haw, J. D. Holmes, and M. A. Morris, "In situ' hard mask materials: a new methodology for creation of vertical silicon nanopillar and nanowire arrays," Nanoscale, vol. 4, no. 24, pp. 7743-7750, 2012.

[13] T. Hirai, M. Leolukman, C. C. Liu et al., "One-step directpatterning template utilizing self-assembly of POSS-containing block copolymers," Advanced Materials, vol. 21, no. 43, pp. 4334-4338, 2009.

[14] T. Ghoshal, T. Maity, J. F. Godsell, S. Roy, and M. A. Morris, "Large scale monodisperse hexagonal arrays of superparamagnetic iron oxides nanodots: a facile block copolymer inclusion method," Advanced Materials, vol. 24, no. 18, pp. 2390-2397, 2012.

[15] T. Thurn-Albrecht, J. Schotter, G. A. Kastle et al., "Ultrahighdensity nanowire arrays grown in self-assembled diblock copolymer templates," Science, vol. 290, no. 5499, pp. 2126-2129, 2000 .
[16] I. W. Hamley, "Nanostructure fabrication using block copolymers," Nanotechnology, vol. 14, no. 10, pp. R39-R54, 2003.

[17] J. Y. Cheng, C. A. Ross, H. I. Smith, and E. L. Thomas, "Templated self-assembly of block copolymers: top-down helps bottom-up," Advanced Materials, vol. 18, no. 19, pp. 2505-2521, 2006

[18] D. Borah, S. Rasappa, S. Ramsankar et al., "Orientation and alignment control of microphase-separated PS-b-PDMS substrate patterns via polymer brush chemistry," ACS Applied Materials \& Interfaces, vol. 5, no. 1, pp. 88-97, 2013.

[19] N. L. Y. Wu, K. D. Harris, and J. M. Buriak, "Conversion of bilayers of PS-b-PDMS block copolymer into closely packed, aligned silica nanopatterns," ACS Nano, vol. 7, no. 6, pp. 55955606, 2013.

[20] J. G. Son, K. W. Gotrik, and C. A. Ross, "High-aspect-ratio perpendicular orientation of PS-b-PDMS thin films under solvent annealing," ACS Macro Letters, vol. 1, no. 11, pp. 12791284, 2012.

[21] S. W. Hong, X. Gu, J. Huh, S. Xiao, and T. P. Russell, "Circular nanopatterns over large areas from the self-assembly of block copolymers guided by shallow trenches," ACS Nano, vol. 5, no. 4, pp. 2855-2860, 2011.

[22] K. Galatsis, K. L. Wang, M. Ozkan et al., "Patterning and templating for nanoelectronics," Advanced Materials, vol. 22, no. 6, pp. 769-778, 2010.

[23] C.-C. Liu, P. F. Nealey, A. K. Raub et al., "Integration of block copolymer directed assembly with 193 immersion lithography," Journal of Vacuum Science and Technology B, vol. 28, no. 6, pp. B30-B34, 2010.

[24] D. Borah, S. Ramsankar, S. Rasappa, B. Kosmala, J. D. Holmes, and M. A. Morris, "Swift nanopattern formation of PS-bPMMA and PS-b-P DMS block copolymer films using a microwave assisted technique," ACS Nano, vol. 7, no. 8, pp. 6583-6596, 2013.

[25] S. Ndoni, C. M. Papadakis, F. S. Bates, and K. Almdal, "Laboratory-scale setup for anionic polymerization under inert atmosphere," Review of Scientific Instruments, vol. 66, no. 2, pp. 1090-1095, 1995.

[26] S. Ndoni, P. Jannasch, N. B. Larsen, and K. Almdal, "Lubricating effect of thin films of styrene-dimethylsiloxane block copolymers," Langmuir, vol. 15, no. 11, pp. 3859-3865, 1999. 

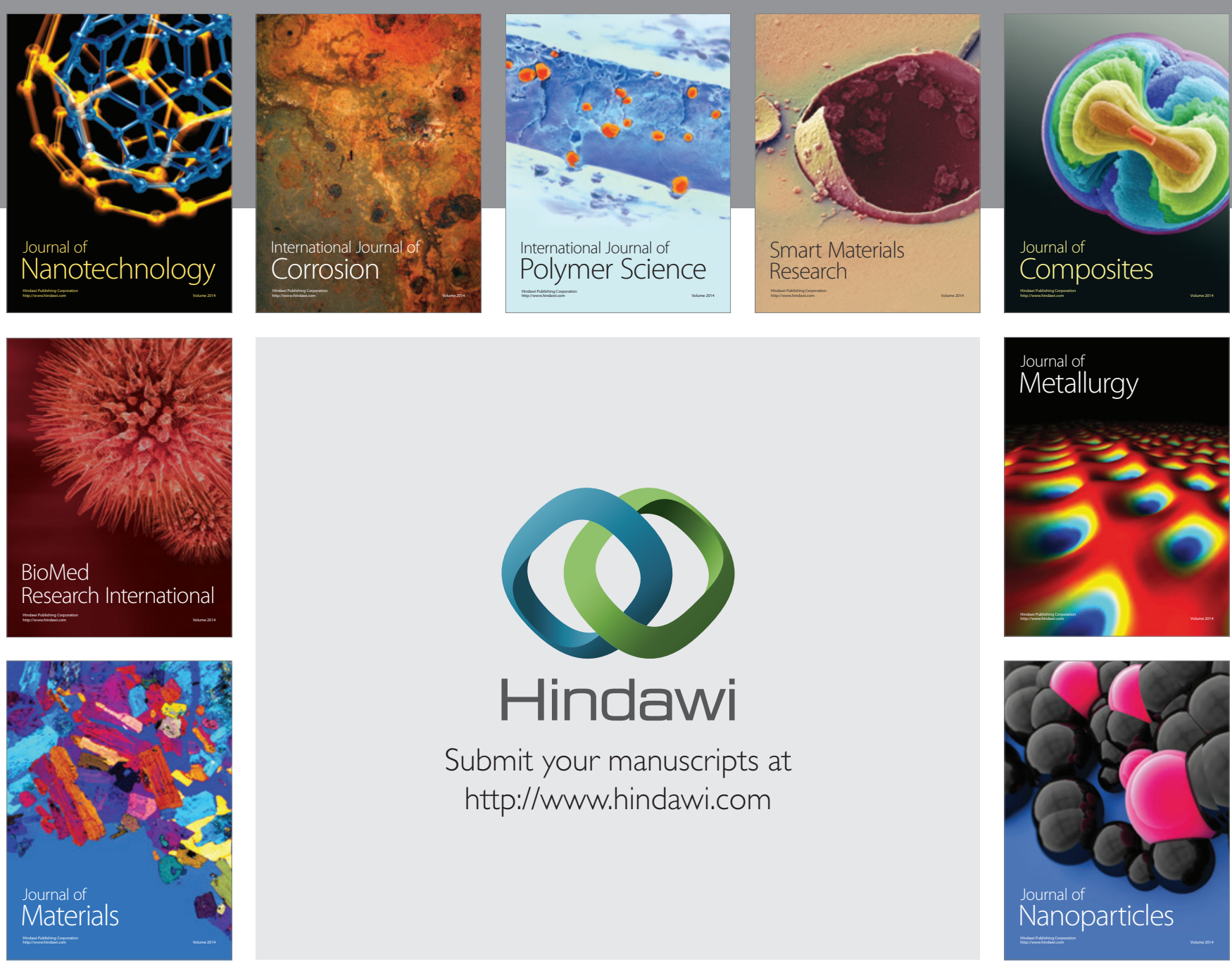

Submit your manuscripts at http://www.hindawi.com
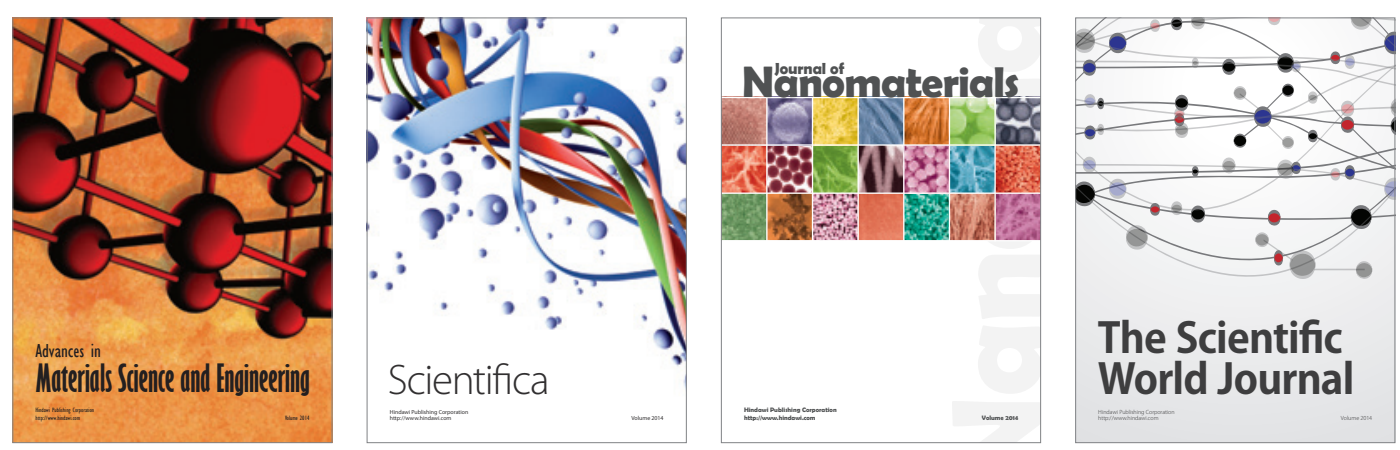

\section{The Scientific World Journal}
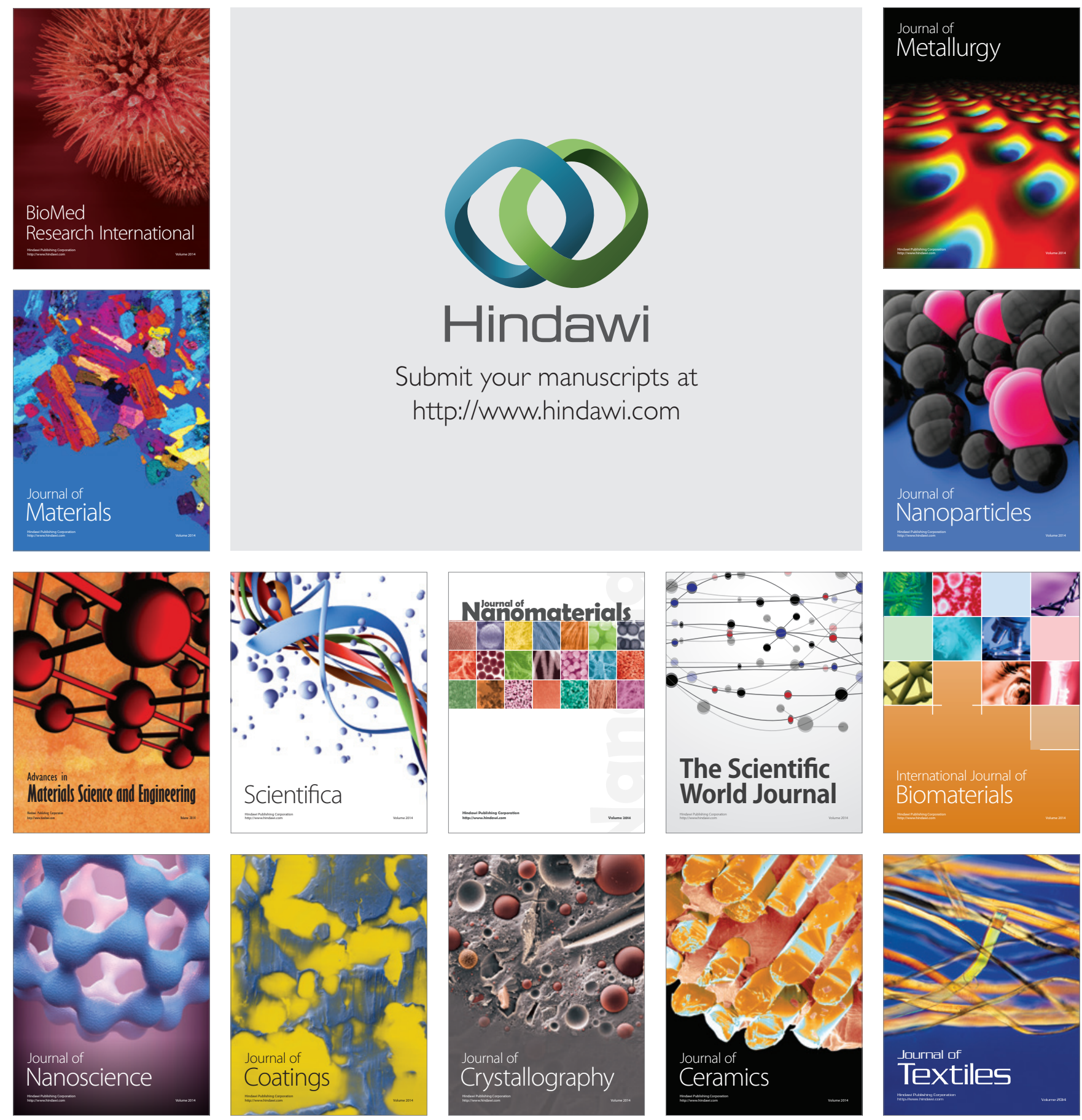